Multidisciplinary

SCIENTIFIC JOURNAL OF MARITIME RESEARCH

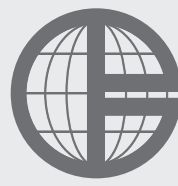

University of Rijeka

Faculty of Maritime

Studies Rijeka
Multidisciplinarni

znanstveni časopis

POMORSTVO

https://doi.org/10.31217/p.32.2.11

\title{
A Hybrid MCDM Approach to Transshipment Port Selection
}

\author{
Matthew Sumner ${ }^{1}$, Igor Rudan ${ }^{2}$ \\ ${ }^{1}$ Graduate student at University of Rijeka, Faculty of Maritime Studies, Rijeka, Croatia, e-mail: matthewsumner@alumni.harvard.edu \\ ${ }^{2}$ Department of Nautical Sciences, University of Rijeka, Faculty of Maritime Studies, Rijeka, Croatia, e-mail: rudan@pfri.hr
}

\section{ARTICLE INFO}

\section{Review article}

Received 14 November 2018

Accepted 3 December 2018

Key words:

Transshipment Port Choice

MCDM

Best-Worst Method

Artificial Bee Colony Algorithm

\section{Introduction}

Bearing in mind that the technology advances allows transportation by sea to be faster and cost effective, the container shipping segment has achieved a rapid growth in recent decades [56]. In order to benefit from the economies of scale, container vessels have been growing in size [32]. The growth of the container shipping has prompted container ports to accommodate large vessels and compete for higher turnaround of cargo. Studies have shown that the most effective method of liner transportation is to ship between larger hubs and then use feeder services to distribute cargo to smaller locations, which helps in minimizing empty slots onboard and optimizes cargo handling [39]. In line with the global expansion of container shipping, liner shipping companies have a unique responsibility of selecting the optimal transshipment ports. Considering that transshipment port costs are a significant part of operational costs [58], selecting the most cost effective option requires analysis of multiple criteria. Commercial factors are the most important segment of the decision making for any private ship owner; however, environmental externalities and political offset plays major role as well. Therefore, not only cost plays an important role in transshipment port selection, but also proximity to main navigational routes, proximity to hinterland and feeder network, geographical factors, administrative and other relevant factors have a significant impact on decision making process.

While transshipment port selection is not a novel domain in the Operations Research field, there is a gap in knowledge about complexities of transshipment port operations and optimization of algorithmic modeling. Considering the dynamic transshipment port environment and or conflicting criteria assessed when selecting ports, it is hard to achieve single optimal solution, but rather a set of various solutions where users practice compromise and preference in selecting the solution that is the best fit. Therefore, we can define transshipment port selection as multiple criteria decision-making (MCDM) problem. In this paper, we adopt a hybrid MCDM method to find the optimal transshipment port maintaining computational efficiency. Therefore the main scope of this review is to present a viable model that will evaluate transshipment port selection. The model is split in two phases: pairwise selection via Best-Worst Multi-Criteria Selection Method followed by the algorithmic expression based on Artificial Bee Colony modeling. 
The structure of this paper is as follows. In Section 2 , we review the available bibliography relevant to the subject of port selection. Section 3 provides a mathematical expression of the model with Best Worst Method utilization, while Chapter 4 delivers computational solution based on $\mathrm{ABC}$ algorithm design to ensure proper path (transshipment port) selection. Section 5 delivers conclusion and discussion of the presented model with key findings and directions for further analysis.

\section{Literature Review}

Considering the global market growth, most of the liner shippers are finding new ways of controlling and minimizing costs in order to capitalize on their competitive advantage. One of the ways to control operating costs is selection of optimal transshipment ports. Studies have confirmed that cost cutting is in the focus of transshipment port selection criteria $[9,10,24,33,34,35,59]$. However, various transshipment port operational costs are not the only criteria for the transshipment port selection; factors such are geographical location, size of the hinterland, proximity to main navigational routes, meteo-oceanological conditions, proximity to custom zones, administrative and operational efficiency, etc. should also be taken into consideration $[34,38,60]$. Finding the optimal transshipment port using a large number of criteria in an uncertain and complex environment is not an easy task. Several approaches have been noted dealing with the port selection problem, but only few attempted to resolve complex selection in an uncertain environment.

Chou et al. [11] and Ugboma et al. [55] analyzed MCDM approaches to port selection; however the analysis considered only the view of shipper with tramp traffic, while in this study we aim to evaluate selection of transshipment ports from the perspective of liner shipper. The main focus is to determine competitiveness through various sets of subjective criteria to evaluate optimal transshipment ports. Port and route selection has been an intrinsic part of Operations Research; however compared to several other application areas, transshipment port selection is still considered a young domain. Several models with appropriate computational methodologies to resolve MCDM problems have been developed by scholars, though there are gaps in computational efficiency and reliability. The proposed hybrid model is developed to aid bridging that gap and to ensure optimal transshipment port selection according to the user set criteria.

Tsamboulas et al. [54] and Celik et al. [8] researched the use of MCDM in evaluating transportation systems. Perez et al. [43] found that 58 different MCDM techniques have been used in the field of passenger transportation since 1982. Kavaliauskas [30] introduced notation in 2008 that decision-making process within the field of transportation has to include economic, social and environmental factors. Belton and Stewart [4] concluded that decision makers have to base their choices on all relevant facts for the process they are evaluating. Decision-making is a dynamic category that requires careful approach for each task and rarely the same evaluating criteria can be applied to other scenarios. Kovacic and Dundovic [31] used a simple MCDM technique to evaluate importance of the systematic understanding of the integrated management in port location selection with sustainable coastal development in mind. Mrvica et al. [37] conducted a detailed study of the criteria for selection of ports when connecting mainland and islands with passenger ro-ro vessels. Similarly Rozic et al. [49] used a combination of various MCDM methods to determine the optimal location for inland terminals. Mardani et al. [36] delivered the extensive overview of the state of the art literature covering multiple fields in which MCDM techniques were used. Total of 89 papers across the 39 journals published from 1993 to 2015 were under systematic review and it is evident that hybrid MCDM methods are most commonly used, followed by AHP and Fuzzy-AHP techniques. These are followed by other MCDM techniques such are TOPSIS, ANP, DEMATEL, PROMETHEE, VIKOR, ELECTRE, and similar. Additionally, Gulic et al. [16] gave an overview of nature inspired metaheuristics for optimization and selection of container terminals.

The most popular MCDM methods in real sector and academia have been: AHP (Analytic Hierarchy Process), which was developed by Saaty [50, 51, 52]; TOPSIS (Technique for Order of Preference by Similarity to Ideal Solution), developed by Hwang et al. [22], while enhanced by Olson [40]. Roy [46, 47, 48] established ELECTRE (ELimination Et Choix Traduisant la REalité) (ELimination and Choice Expressing REality) method in order to improve appropriate assignment of weights. In order to solve decision problems with conflicting and noncommensurable criteria, taking in consideration that compromise is acceptable for the observer, Opricovic and Tzeng [41] developed VIKOR (VIseKriterijumska Optimizacija I Kompromisno Resenje) method in 1979. Brans with group of researchers advanced MCDM field with a novel method called PROMETHEE $[5,6,7]$. There are many other MCDM methods developed, including the hybrid versions, which are thoroughly reviewed by Mardani et al. [36].

When focusing on the port selection problem, authors commonly suggest application of fuzzy MCDM techniques. Lirn, Thanopoulou, and Beresford [33] assessed port alternatives by applying fuzzy AHP method. Chou [9] used a fuzzy MDM method to evaluate criteria for transshipment container port selection problem. Fuzzy evidential reasoning has been used by Yeo et al. [60] to develop a decision support tool for port selection. Kadaifci [24] used Fuzzy rule-bases method to resolve container transshipment terminal selection problem.

Most of the mentioned MCDM methods use pairwise comparison in order to develop a structured decision matrix. Pairwise comparison method was initially developed by Thurstone [53] and improved by the academia throughout the recent decades. Experts in related field usually provide pairwise criteria and then methods would deliver estimated results in order to aid the decision maker. The most significant challenge of pairwise comparison methods is the inconsistency of pairwise comparison matrices [14, 
19]. In order to address pairwise comparison inconsistencies, Rezaei [44] developed Best-Worst method (BWM) to provide more structured and efficient way of comparison execution. Using the real world example, Rezaei [44] presented statistical data of BWM method outperforming the AHP method by achieving better consistency ratio with minimal violation, total deviation and conformity. It is, therefore, a selected method for pairwise comparison of criteria in the transshipment port selection problem.

Finding the optimal transshipment port can be classified as NP-hard combinatorial optimization problem. Considering the high number of decision parameters, classical optimization methods are considered inefficient when solving optimization problems. When dealing with higher number of constraint and objective functions, classical optimization methods are unable to cope with increased numerical steps and require long computational time. Cordeau et al. [12] explored heuristic approaches to solve vehicle routing problems and find suitable path. Artificial Bee Colony algorithm is one of the recently developed solutions that require substantially shorter time to find optimized solutions. The ABC algorithm was developed by Karaboga [25] and research is continuing in finding the best performing and improved version of the algorithm. Transshipment port selection problem could be defined as Travelling Salesman Problem (TSP), where salesman has to visit all cities in a given set and return to the starting point using shortest routes and covering the smallest total distance. The problem should be set up with constraints, rewards and should result with the route that incurs the lowest cost [57]. Through biological observation of bees and ants, it was determined that their behavior could be used to develop algorithms that have potential in resolving routing problems.

To the best of our knowledge, this paper is one of the first works to incorporate Best-Worst MCDM method to categorize and weigh decision-making parameters and $\mathrm{ABC}$ algorithm to find the optimal transshipment port.

\section{Best-Worst Multi-Criteria Decision Making Structure}

Within this chapter we deliver notation, basic assumptions and introduce best-worst method approach to classify and weigh MCDM criteria for the analysis of the transshipment port selection problem. The Best-Worst Method (BWM) is a novel MCDM method based on a pairwise comparison of the best and the worst criteria with other criteria in order to derive the appropriate criteria weights. Rezaei [44] compared the BWM method with the AHP method and demonstrated that BWM method performs better than AHP because BWM is based on vectors and it requires fewer comparisons, while the reliability of weights derived in BWM is higher than AHP with proven level of consistency. Also, BWM uses integers only and it is easier to use than other MCD methods.

Even though pairwise comparison is extensively used and well-established method [53], lack of consistency is the ubiquitous problem [19] that BWM is determined to resolve. The common course of action to resolve inconsistencies was to revise the criteria matrix until the consistency is achieved, but this was shown not to be successful [29]. BWM is introducing structured way of criteria pairwise comparison. By selecting the best and worst alternative among the number of criteria, pairwise selection becomes structured, faster and less complex. It is important to state that selecting best and worst alternatives is a complex, and often subjective, task. The decision-maker will either have a thorough knowledge of the process, or experts will define criteria where decision-maker can select best and worst alternatives.

When selecting transshipment ports, decision-maker has to develop criteria set for each alternative and finally select the optimal solution. In order to efficiently select the transshipment port, adaptation of Best-Worst MCDM with Artificial Bee Colony optimization algorithm is considered. The proposed integrated method is comprised of the following steps and based on Rezaei's [44] work on Best-Worst Method and Karaboga's [25] work on honeybee swarm for numerical optimization.

Step 1 - Identify the set of alternatives. In this step we have to select all the alternatives relevant for our decision-making task $\left\{\mathrm{p}_{1}, \mathrm{p}_{2}, \mathrm{p}_{3}, \ldots, \mathrm{p}_{\mathrm{n}}\right\}$. As soon as the initial demand for the transshipment port is evident in the market, the ship owner will try to evaluate potential ports for selection. Even though the selection can appear intuitive, there are many criteria that will affect the selection process. Therefore, the first step is to determine a list of all potential transshipment ports and evaluate each alternative according to the relevant criteria described in the step 2 . In the real world scenarios, ship owners evaluating transshipment port candidates could consider compensatory criteria as well, where a particularly good discount for that ship owner is offered, or ship owner established special relationship with local governance.

Step 2 - Criteria selection for each of the alternatives. After the selection of alternatives has been completed, we continue selection of the transshipment port by creating sets of criteria for each of the alternatives. When designing criteria sets, or assigning weights, the most efficient approach is to use previous experiences; therefore the most common approach is to consult experts in the field of interest. For instance when selecting a vessel suitable for our transport of freight, the decision criteria could be age of vessel $\left(c_{1}\right)$, charter price $\left(c_{2}\right)$, crew experience matrix $\left(c_{3}\right)$, fleet reliability $\left(c_{4}\right)$, lost-time-injury safety records $\left(\mathrm{c}_{5}\right)$, environmental impact factors $\left(\mathrm{c}_{6}\right)$, vetting and Port State Control performance $\left.\left(\mathrm{c}_{7}\right)\right\}$.

In order to design a set of relevant criteria for the transshipment port selection problem, several authors consulted experts from the industry. Considering the growth rate of competition, delivery schedules and customers' demand, the main focus of all ship owners is to cut cost and deliver products on time. In line with this, authors most commonly mention cost as criteria for port 
selection, focusing on various port charges $[9,10,33,59]$ and container handling fees [34, 35]. Many authors consulted experts to derive various other criteria; such are geographical location, political stability, port administration, proximity to main navigation routes, port facility attributes, time efficiency, hinterland economy, logistic costs, port structure, adaptability to ship owner's change in demand, proximity to feeder services, and development of auxiliary infrastructure $[17,34,35,38,59,60]$.

Even though categories could be selected by interested ship owner on case to case basis, literature review revealed 47 criteria that experts linked with transshipment port selection problem. Authors added three additional decision criteria to the pool. In the literature meteorological and oceanological factors were not considered, where in the real sector meteorological dynamics play significant role in scheduling and reliability of service. Fog is one of the three criteria, selected due to its adverse effects on shipping. Poor visibility often slows down vessels entering and leaving ports, reduces speed of port operations and container handling operations. A strong wind accompanied by rough sea is second meteorological criteria considered. Considering the windage area of modern container ships, strong wind can present very difficult operational conditions and can possibly prevent vessel of entering ports or cease crane operations alongside the designated quay. Consistent strong winds are going to delay operations and cause backlog. Similarly and complementary to strong winds, high seas can also cause harbor operations to stop until the weather improves. If there is cyclic weather pattern, ship owner will take in consideration calmer ports for the transshipment ports. Finally, the last meteorological criterion to be considered is ice, which is more predictable than fog, wind or high seas. Ice is easier to predict in ports, but the potential of damaging ships approaching and leaving ports is large due to the uncertainty of icebergs and floating ice sheets position in the adjacent waterways. Combining transshipment port criteria from literature review and authors, we gather 50 port selection criteria that are used as input data for the transshipment port selection problem. In order to achieve clearer overview, authors further categorized transshipment port selection criteria into the eight major criteria and associated sub-criteria. This is necessary in order to ensure that the adapted Best-Worst MCDM is effective.

While Table 1 provides an overview of each criterion and sub-criteria, Figure 1 portrays decision hierarchy in determining the optimal transshipment port. After the

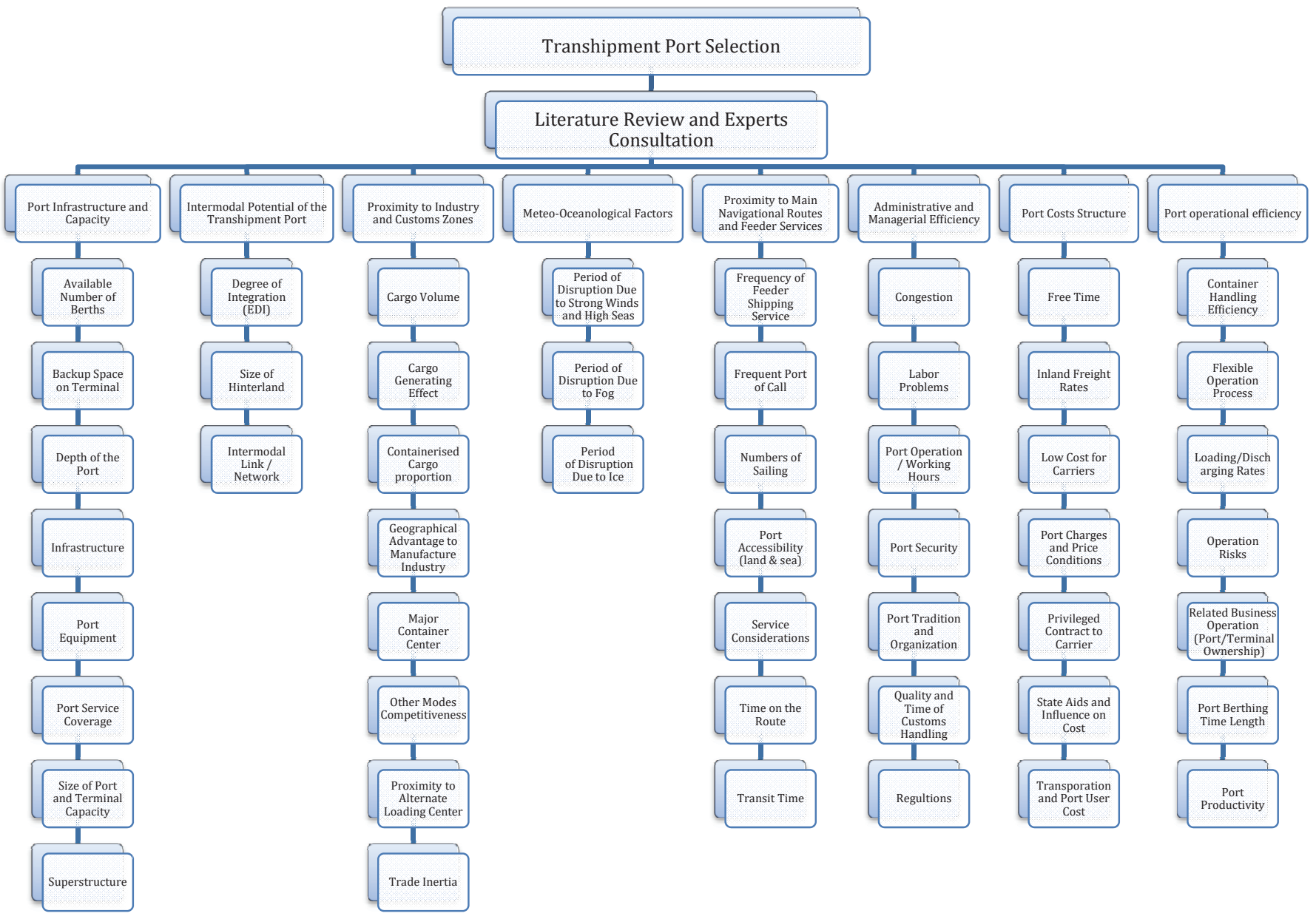

Figure 1 Decision Hierarchy in Determining Optimal Transshipment Port 
Table 1 Qualitative Categorization of Transshipment Port Selection Criteria

\begin{tabular}{|c|c|c|c|}
\hline CRITERION & Component & MARK & SUB-CRITERION \\
\hline \multirow{6}{*}{$\mathrm{C} 1$} & \multirow{6}{*}{$\begin{array}{l}\text { Transshipment Port } \\
\text { Infrastructure and } \\
\text { Capacity }\end{array}$} & $\mathrm{c} 11$ & Available Number of Berths \\
\hline & & $\mathrm{c} 12$ & Backup Space on Terminal \\
\hline & & $\mathrm{c} 14$ & Infrastructure \\
\hline & & $\mathrm{c} 15$ & Port Equipment \\
\hline & & $\mathrm{c} 16$ & Port Service Coverage \\
\hline & & $\mathrm{c} 18$ & Superstructure \\
\hline \multirow{3}{*}{$\mathrm{C} 2$} & \multirow{3}{*}{$\begin{array}{l}\text { Intermodal Potential } \\
\text { of the Transshipment } \\
\text { Port }\end{array}$} & $\mathrm{c} 21$ & Degree of Integration (EDI) \\
\hline & & $\mathrm{c} 22$ & Size of Hinterland \\
\hline & & $\mathrm{c} 23$ & Intermodal Link / Network \\
\hline \multirow{5}{*}{ C3 } & \multirow{5}{*}{$\begin{array}{l}\text { Proximity to Industry } \\
\text { and Customs Zones }\end{array}$} & c31 & Cargo Volume \\
\hline & & c35 & Major Container Center \\
\hline & & c36 & Other Modes Competitiveness \\
\hline & & c37 & Proximity to Alternate Loading Center \\
\hline & & c38 & Trade Inertia \\
\hline \multirow{3}{*}{$\mathrm{C} 4$} & \multirow{3}{*}{$\begin{array}{l}\text { Meteo-Oceanological } \\
\text { Factors }\end{array}$} & $\mathrm{c} 41$ & Period of Disruption Due to Strong Winds and High Seas \\
\hline & & $\mathrm{c} 42$ & Period of Disruption Due to Fog \\
\hline & & $\mathrm{c} 43$ & Period of Disruption Due to Ice \\
\hline \multirow{2}{*}{$\mathrm{C} 5$} & \multirow{2}{*}{$\begin{array}{l}\text { Proximity to Main } \\
\text { Navigational Routes } \\
\text { and Feeder Services }\end{array}$} & c51 & Frequency of Feeder Shipping Service \\
\hline & & c52 & Frequent Port of Call \\
\hline \multirow{6}{*}{ C6 } & \multirow{6}{*}{$\begin{array}{l}\text { Administrative and } \\
\text { Managerial Efficiency }\end{array}$} & c62 & Labor Problems \\
\hline & & c63 & Port Operation / Working Hours \\
\hline & & c64 & Port Security \\
\hline & & c65 & Port Tradition and Organization \\
\hline & & c66 & Quality and Time of Customs Handling \\
\hline & & c67 & Regulations \\
\hline \multirow{7}{*}{$\mathrm{C} 7$} & \multirow{7}{*}{$\begin{array}{l}\text { Transshipment Port } \\
\text { Costs Structure }\end{array}$} & c71 & Free Time \\
\hline & & c72 & Inland Freight Rates \\
\hline & & c73 & Low Cost for Carriers \\
\hline & & c74 & Port Charges and Price Conditions \\
\hline & & c75 & Privileged Contract to Carrier \\
\hline & & c76 & State Aids and Influence on Cost \\
\hline & & c77 & Transportation and Port User Cost \\
\hline \multirow{6}{*}{$\mathrm{C} 8$} & \multirow{6}{*}{$\begin{array}{l}\text { Transshipment Port } \\
\text { Operational Efficiency }\end{array}$} & c81 & Container Handling Efficiency \\
\hline & & c82 & Flexible Operation Process \\
\hline & & c83 & Loading/Discharging Rates \\
\hline & & c84 & Operation Risks \\
\hline & & c85 & Related Business Operation (Port/Terminal Ownership) \\
\hline & & c86 & Port Berthing Time Length \\
\hline
\end{tabular}


initial transshipment port candidates selection and definition of all criteria required for choosing optimal transshipment port, ship owner would commence with analysis in order to source the unique solution. Pairwise comparison has to be done on both sub-criteria and criteria level in order to achieve crisp result.

Step 3 -Define the best and the worst criteria. In this step we should determine the best (the most important from the decision-maker's view) and the worst (the least important) criteria in each set. It is possible to get more than one best or worst criteria, but in that case, we can chose arbitrary. The goal of this step is only to select the best and the worst and not to make any comparisons.

Step 4 - Best-to-Others vectors. In this step we determine the preference of the best criterion over the other criteria in a designed set. Any scale can be used. The resulting Best-to-Others vector would be:

$$
A_{B}=\left(a_{B 1}, a_{B 2}, a_{B 3}, \ldots, a_{B n}\right),
$$

where $\alpha_{B j}$ indicates the preference of the best criterion B over criterion $j$.

Step 5 - Others-to-Worst vectors. Our goal in this step is to determine the preference of all criteria over the worst criterion using the same scale as in the previous step. The resulting Others-to-Worst vector would be:

$$
A_{W}=\left(a_{1 W}, a_{2 W}, a_{3 W}, \ldots, a_{n W}\right),
$$

where $a_{j w}$ indicates the preference of the criterion $\mathrm{j}$ over the worst criterion $\mathrm{W}$.

Step 6 - Finding the optimal weight. The final step of BWM is assigning and finding the optimal weights $\left(w_{1}^{*}, w_{2}^{*}\right.$, $\left.w_{3}^{*}, \ldots, w_{n}^{*}\right)$. The optimal weight of a selected criteria is the one where, for each pair of $w_{B} / w_{j}$ and $w_{j} / w_{W^{\prime}}$ we have $w_{B} /$ $w_{j}=a_{B j}$ and $w_{j} / w_{W}=a_{j w^{\circ}}$. In order to ensure these conditions are satisfied for all $j$ [44], we aim to find solution for the following minmax model:

$$
\min \max _{j}\left\{\left|\frac{w_{B}}{w_{j}}-a_{B j}\right|,\left|\frac{w_{j}}{w_{W}}-a_{j W}\right|\right\}
$$

s.t.

$\sum_{j} w_{j}=1$

$w_{j} \geq 0$, for all $j$

Transshipment port selection is defined by a large set of selection criteria. It is possible to find single solution for optimization models with two or three criteria; however when criteria set is large, multiple optimal solutions are possible where users have to select a system of weighs to rank solutions. Considering the fact that the scope of the transshipment port selection is to find the optimal port, linear programming formulation provides an option for a single optimal solution [45]. In order to apply linear pro- gramming method to find a single optimal solution, it is necessary to transform the set $\left\{\left|\frac{w_{B}}{w_{j}}-a_{B j}\right|,\left|\frac{w_{j}}{w_{W}}-a_{j W}\right|\right\}$, so that we can minimize the maximum among the set of $\left\{\left|w_{B}-a_{B j} w_{j}\right|,\left|w_{j}-a_{j w} w_{W}\right|\right\}$.

It is now possible to transfer problem (3) to the following linear programming formulation:

$\min \xi^{L}$

s.t.

$\left|w_{B}-a_{B j} w_{j}\right| \leq \xi^{L}$, for all $j$

$\left|w_{j}-a_{j w^{\prime}} w_{w}\right| \leq \xi^{L}$, for all $j$

$\sum_{j} w_{j}=1$

$w_{j} \geq 0$, for all $j$

The $\min \xi^{*}$ problem has a unique solution that allows us to obtain optimal weights $\left(w_{1}^{*}, w_{2}^{*}, \ldots, w_{n}^{*}\right)$ and the optimal value $\xi^{*}$, which is furthermore used as a consistency ratio of the comparison pairs. Closer $\xi^{L^{*}}$ is to a zero value, more consistent are the comparisons.

With transshipment port selection defined as linear programming problem, we approach to solution with iterative heuristics. In order to have accurate results, we have to find optimized paths for which we will use Artificial Bee Colony algorithm (ABC), which is based on honeybee swarm intelligence to find augmented paths. Solution methods are detailed and presented in the next chapter.

\section{Transshipment Port Selection Heuristic with ABC Algorithm}

We can define each transshipment port candidate as a set of available paths that can satisfy ship owner's origindestination (OD) requirements. Each path consists of costs and prices that drive path selection. The pondering value for each path is defined by the associated selection criteria and consistency factor.

In our case, we have a ship owner that has to decide which port to select among the set of potential transshipment ports. In order to find the optimal port, combined $\mathrm{ABC}$ algorithm and BWM MCDMA method is available to ship owner to eliminate pairwise comparisons with highest consistency ratios. The $\mathrm{ABC}$ algorithm will allow for fast pairwise comparisons of all options iteratively and will maintain lean computation. The most important step is for a ship owner to select all criteria and assign weights for the BWM calculations, after which the ABC algorithm will select the optimal path given the lowest consistency ratios within the BWM model, which will lead towards the transshipment port selection.

In order to solve the transshipment port selection problem, our approach is based on solving the path selection problem after which we feed the results back to one another. This iteration allows us to remove any paths (ports) that have disqualifying criteria. Our transshipment 
port decision variable is $x_{i j, r}$ which represents value of the alternative $p_{i}$ on criterion $c_{j}$ of the decision matrix, while $r$ represents a path (further explanation of the $x_{i j r}$ variable is provided in the next chapter). Our goal is to determine any disqualifying paths before proceeding with pairwise comparison. Naturally, liner shipping company selecting transshipment port will choose profit-maximizing path to serve customers' OD demand. We continue with the iterations until the BWM consistency ratio $\xi^{*}$ results with a value as close as to zero. These are the algorithmic steps:

\section{Step 1: Definition}

For each liner shipping company in the model $r \in R$ we initialize the parameters. We commence with the number of iterations $n$. This is followed by selecting criteria of each alternative, while the ship owner is selecting the best and the worst of the selected criteria. Once all criteria are defined, we commence with path (port) selection. Initially, we set $x_{i j r}=0 \forall r \in R$.

\section{Step 2: Path (port) selection}

After the initial set up of the problem, it is necessary to find the optimal path of the network. In order to solve this problem, we propose using the Artificial Bee Colony (ABC) algorithm that is considered to be suitable and one of the best performing for this kind of problems [1, 3, 27, 28].

In our model, we define the optimization problem as constrained. In case of the constrained optimization problems, we have to optimize two functions, the objective function and constraint violation function [18]. There were several approaches to solve constrained optimization problems, namely deterministic and stochastic. Deterministic approaches are less applicable to the real world situations, considering their assumptions of continuity and differentiability of the objective function [13]. However, stochastic approaches, such are Evolutionary Algorithms, Genetic Algorithms, or Particle Swarm Algorithms (PSO) do not make such assumptions and have been successfully used on constrained optimization problems in the past $[23,21,42]$.

Adapted from Karaboga [25] and Basturk and Karaboga [2], we model ABC algorithmic approach to path selection, where the position of a food represents possible optimization solutions (transshipment port candidates) and the nectar amount of a food represents the best fitting solution based on the lowest consistency ratio $\xi^{*}$ among the alternatives available. The ABC algorithm consists of three groups of artificial bees: employed bees, onlooking bees and scout bees. There is only one bee employed for each position of a food. Therefore, the number of employed and onlooking bees are equal to the number of solutions. Employed bee whose food source has been abandoned becomes scout bee. Initially, $\mathrm{ABC}$ generates a randomly distributed initial population $\Pi(G=0)$ of $S N$ food source - solutions, where $S N$ represents the size of population. Each solution in the population $y_{i}(i-1,2, \ldots, S N)$ is determined by the optimization parameters (selection criteria by the user for each alternative). Therefore, D stands for the number of optimization parameters. After the initial population, further solutions population depends on employed bees' repeated search cycles, $C=1,2, \ldots, M C N$. Each employed bee modifies solution (position) depending on the nectar amount of the new position. If the new position has higher nectar amount (lower consistency ratio $\xi^{L^{\dagger}}$ ), the bee memorizes the new position and forgets the old one. Alternatively, employed bee keeps the position of the previous nectar amount in her memory. After the search of all bees is completed, they share the nectar information of the food sources (possible solutions) with the onlooker bees on the dance area. An onlooker bee is processing the information gathered by all employed bees and choses the optimal food source by assigning probability based on the nectar amount. Similarly like the employed bee, an onlooking bee modifies positions in her memory depending on the nectar amount.

We first need to calculate probability value associated with each food source in the population, which is done by the onlooking bees. The probability value $p_{i}$ is calculated as below:

$$
p_{i}=\frac{f i t_{i}}{\sum_{n=1}^{S N} f i t_{n}}
$$

where fit is the fitness value of the solution $i$, which is proportional to the nectar amount of the observed position. In the case of our model, the fitness value can be determined by the following expression:

$$
f i t=\frac{\sum_{j=1}^{n} w_{j} x_{i j r}^{n o r m}}{\xi L^{*}}
$$

where $w_{j}$ is the optimal weight of the option calculated by the use of the best-worst method. After obtaining weights, we use normalized scores of the alternatives on the different criteria for different transshipment ports, $x_{i i r}^{\text {norm }}$, to calculate the final score per alternative for transshipment port (path) $r$, which is the integer numerator of the expression (6). We use the following expression to obtain normalized scores of the alternatives:

$$
x_{i j r}^{\text {norm }}=\left\{\begin{array}{c}
\frac{x_{i j r}}{\max \left\{x_{i j r}\right\}}, \text { if } x \text { is positive (such as quality of service), } \\
1-\frac{x_{i j r}}{\max \left\{x_{i j r}\right\}}, \text { if } x \text { is negative (such as cost of shipping). }
\end{array}\right.
$$

In order to produce a candidate food position from the old one in the memory, we use adapted expression for constrained optimization problems [26]:

$$
v_{i j}= \begin{cases}x_{i j r}^{\text {norm }}+\phi_{i j}\left(x_{i j r}^{\text {norm }}-x_{k j r}^{\text {norm }}\right) & , \text { if } R_{j}<M R \\ x_{i j r}^{\text {norm }} & \text {, otherwise }\end{cases}
$$

where $k \in\{1,2, \ldots, S N\}$ is randomly chosen index. Even though $k$ is a randomly chosen number, it has to be different than $i . \phi_{i j}$ is a random number between $[-1,1]$. It controls the production of a neighbor food source position around $x_{i j r}^{\text {norm }}$ and the modification represents the comparison of the neighbor food positions visually by the bee. $R$ is randomly chosen real number with a range $[0,1]$ and 
$j \in\{1,2, \ldots, D\} . M R$ is our modification rate and its role is to control modification of the parameter $x_{i j r}^{\text {norm }}$. For the constrained optimization problems, the $\mathrm{ABC}$ algorithm produces artificial scouts at a predetermined period of cycles in order to discover food sources randomly. This is another control parameter of the ABC algorithm and it is called Scout Production Period (SPP). At each SPP cycle the model determines if there are abandoned food sources, and if there are, scout production is carried out.

When the bees abandon the food source, the scouts select new food source. In the ABC algorithm, if the food source cannot be further improved through predetermined number of cycles, then the food source is abandoned. Therefore, the number of predetermined cycles is important control parameter of the $\mathrm{ABC}$ algorithm and is considered a limit for abandonment. If we assume that the abandoned source is $x_{i r}^{\text {norm }}$ and $j \in\{1,2, \ldots, D\}$, then the scout discovers a new food source to be replaced with $x_{i r}^{\text {norm }}$ [25]:

$$
x_{i r}^{n o r m, j}=x_{r, \min }^{n o r m, j}+\operatorname{rand}(0,1)\left(x_{r, \max }^{n o r m, j}-x_{r, \min }^{n o r m}\right)
$$

Additionally, in order to use ABC algorithm in constraint optimization environment, the classic selection process has to be alternated with Deb's heuristic constrained handling method [15]. In their research of Genetic Algorithms, Goldberg and Deb investigated usability of GA algorithms for constrained optimization problems and delivered three heuristic rules: 1) Any feasible solution is preferred to any infeasible solution, 2) if there are two feasible solutions, the one with better objective function value is preferred, and 3) if there are two infeasible solutions, the one having smaller constraint violation is preferred.

Finally, pseudo-code of the ABC algorithm for transshipment port selection is as follows:

1: $\quad$ Setting up the population of potential transshipment port options.

2: Select the criteria, utilize the BWM to find optimal weights and initialize the population of solutions $x_{i j r}^{\text {norm }}$, $i=1 \ldots S N, j=1 \ldots D$

3: Evaluate the population

4: $\quad$ cycle $=1$

\section{5: repeat}

6: Produce new solutions $v_{i j}$ for the employed bees by using (8) and evaluate them

7: Apply selection process utilizing Deb's constrained optimization method

8: Verify all criteria for all potential ports (paths) and calculate $\xi^{L^{*}}$ using (4)

9: Calculate probability values $p_{i j}$ for the solutions $x_{i j r}^{\text {norm }}$ using (5), (6) and (7)

10: Produce the new solutions $v_{i j}$ for the onlookers from the solutions $x_{i j r}^{\text {norm }}$ selected depending on $p_{i j}$ and evaluate them

11: Apply selection process utilizing Deb's constrained optimization method

12: Determine the abandoned solution for the scout, if exists, and replace it with a new randomly produced solution $x_{i j r}^{\text {norm }}$ by (9)
13: Memorize the best solution achieved so far

14: cycle $=$ cycle+1

15: until cycle $=\mathrm{MCN}$

\section{Step 3: Convergence Test}

In order to perform the convergence test as a final step of the transshipment port selection, we measure changes in consistency ratios of each transshipment port (path) considered between two consecutive iterations. The liner shipping company selecting the transshipment port will have to select the predetermined change level (for example $\frac{\left|\xi^{n, L^{*}}-\xi^{n-1, L^{*}}\right|}{\xi^{n, L^{*}}} \leq 5 \%$ ) at which the process is terminated and when the report with the current results is generated. If the change is not less than predetermined level, we return to the Step 3 with $n=n+1$.

\section{Conclusions}

The Operations Research field has been investigating optimal transshipment port selection models for over three decades now. Nevertheless, finding the optimal transshipment port with accurate and lean computation remains to be of a great interest for liner shipping companies. Considering that transshipment port selection problem is inherently a constrained multi-criteria optimization problem, the focus of this study was to develop an efficient algorithm that can deal with complexity and uncertainty of the transshipment port selection the perspective of a single ship owner.

In line with the aforementioned focus, we deliver a new hybrid MCDM solution that incorporates selection of the most viable options using Best-Worst pairwise comparison methodology to determine solution with the lowest consistency factor and Artificial Bee Colony algorithm to ensure computational efficiency. The main benefit of this approach is the effective and lean algorithmic computation that allows for unsuitable solutions to be removed from the memory and faster convergence with each iteration cycle until the consistency ratio is as closer to a value of zero, making the selected transshipment port optimal for that user. The flexibility of this model is evident through its capability to deal with uncertainty, subjectivity, complexity and bewilderment of multi-criteria decision making.

This work delivers a conceptual foundation upon which real-world simulation is warranted. Therefore, further extension of this study is to motivate liner shipping experts to apply real-world data and verify results. It is necessary to state that our approach to application of the model is static and we deal with information available prior to analysis. Even though this model can deal with larger data set, an additional step to eliminate initial criteria would make computation leaner. In the real world, it is possible that liner shipping companies will have to deal with dynamic and asymmetric information in various stages of transshipment port selection and transportation planning. A model that could incorporate dynamic changes would produce insightful solutions. 


\section{References}

[1] Ab Wahab M.N., Nefti-Meziani S., and Atyabi A. (2015). A Comprehensive Review of Swarm Optimization Algorithms. PLoS ONE 10(5): e0122827.

[2] Basturk, B., Karaboga, D. (2006). An Artificial Bee Colony (ABC) Algorithm for Numeric function Optimization, IEEE Swarm Intelligence Symposium 2006, May 12- 14, 2006, Indianapolis, Indiana, USA.

[3] Behzad, N., and Babak, F. (2016). On the application of artificial bee colony (ABC) algorithm for optimization of well placements in fractured reservoirs; efficiency comparison with the particle swarm optimization (PSO) methodology. Petroleum 2, pp. 79-89.

[4] Belton, V., and Stewart, T. J. (2002). Multiple Criteria Decision Analysis: an Integrated Approach. Springer. 372 p.

[5] Brans, JP., Mareschal, B., and Vincke, P. (1984). PROMETHEE: a new family of outranking methods in multicriteria analysis. In: Brans JP, editor. Operational research. North Holland, Amsterdam: IFORS 84, pp. 477-90.

[6] Brans, JP., and Vincke, P. (1985). Note-A preference ranking organisation method (The PROMETHEE method for multiple criteria decision-making). Management Science. 31, pp. 647-56.

[7] Brans, J-P., Vincke, P., and Mareschal, B. (1986). How to select and how to rank projects: the PROMETHEE method. European Journal of Operational Research. 24, pp. 228-38.

[8] Celik, E., Bilisik, O. N., Erdogan, M., Gumus, A. T., and Baracli, H. (2013). An integrated novel interval type-2 fuzzy MCDM method to improve customer satisfaction in public transportation for Istanbul, Transportation Research Part E: Logistics and Transportation Review 58, pp. 28-51.

[9] Chou, -C.-C. (2007). A Fuzzy MCDM Method for Solving Marine Transshipment Container Port Selection Problems. Applied Mathematics and Computation 186, pp. 435-444.

[10] Chou, -C.-C. (2010). Application of FMCDM Model to Selecting the Hub Location in the Marine Transportation: A Case Study in Southeastern Asia. Mathematical and Computer Modelling 51 (5-6), pp. 791-801.

[11] Chou, C., Chu, C., and Liang, G. (2003). A Transportation Demand Split Model for International Ports in Taiwan Area. Journal of the Eastern Asia Society for Transportation studies 5, pp. 625-637.

[12] Cordeau, J. F., Gendreau, M., Laporte, G., Rotvin, J. Y., and Semet, F. (2002). A guide to vehicle routing heuristics. Journal of Operational Research Society, 53(5), pp. 512-522.

[13] Floudas, C. A., and Pardalos, P. M. (1987). A collection of test problems for constrained global optimization algorithms, In: LNCS. Vol. 455. Springer-Verlag.

[14] Forman, E. H., and Selly, M. A. (2001). Decision by objectives: how to convince others that you are right. World Scientific Publishing Company Incorporated.

[15] Goldberg, D. E., and Deb., K. (1991). A comparison of selection schemes used in genetic algorithms Foundations of Genetic Algorithms, edited by G. J. E. Rawlins, pp. 69-93.

[16] Gulic, M., Maglic, L., and Valcic, S. (2018). Nature Inspired Metaheuristics for Optimizing Problems at a Container Terminal. Scientific Journal of Maritime Research 32, pp. 10-20.

[17] Hasheminia, H., and C. Jiang. (2017). Strategic Trade-Off between Vessel Delay and Schedule Recovery: An Empirical Analysis of Container Liner Shipping. Maritime Policy \& Management 44 (4), pp. 458-473.
[18] Hedar, A., and Fukushima, M. (2006). Derivative-Free Filter Simulated Annealing Method for Constrained Continuous Global Optimization. Journal of Global Optimization 35(4), pp. 521-549.

[19] Herman, M. W., and Koczkodaj, W. W. (1996). A Monte Carlo study of pairwise comparison. Information Processing Letters (57), pp. 25-9.

[20] $\mathrm{Hu}, \mathrm{X}$., and Eberhart, R. (2002). Solving constrained nonlinear optimization problems with particle swarm optimization. In Proceedings of the Sixth World Multi-conference on Systemics, Cybernetics and Informatics.

[21] Hu, X., Eberhart, R. C., and Shi, Y. H. (2003). Engineering optimization with particle swarm, IEEE Swarm Intelligence Symposium, pp. 53-57.

[22] Hwang C-L., Lai, Y-J., and Liu T-Y. (1993). A new approach for multiple objective decision making. Computers \& Operations Research (20), pp. 889-99.

[23] Joines, J. A., and Houck, C. R. (1994). On the use of nonstationary penalty functions to solve nonlinear constrained optimization problems with gas, In: Proc. IEEE Int. Conf. Evol. Comp., pp. 579-585.

[24] Kadaifci, C., Asan U., Serdarasan S., and Arican, U. (2018). A new rule-based integrated decision making approach to container transshipment terminal selection. Maritime Policy \& Management, Published online June-2018.

[25] Karaboga, D. (2005). An Idea Based On Honey Bee Swarm For Numerical Optimization, Technical Report-TR06, Erciyes University, Engineering Faculty, Computer Engineering Department.

[26] Karaboga D., and Basturk B. (2007). Artificial Bee Colony (ABC) Optimization Algorithm for Solving Constrained Optimization Problems. In: Melin P., Castillo O., Aguilar L.T., Kacprzyk J., Pedrycz W. (eds) Foundations of Fuzzy Logic and Soft Computing. IFSA 2007. Lecture Notes in Computer Science, vol. 4529. Springer, Berlin, Heidelberg.

[27] Karaboga, D., and Basturk B. (2008). On the performance of artificial bee colony (ABC) algorithm. Applied Soft Computing 8, pp. 687-697.

[28] Karaboga, D., Gorkemili B., Ozturk, C., and Karaboga, N. (2014). Artificial Intelligence Review 42, pp. 21-57.

[29] Karapetrovic, S., and Rosenbloom, E. S. (1999). A quality control approach to consistency paradoxes in AHP. European Journal of Operational Research (119), pp. 704-18.

[30] Kavaliauskas, P. (2008). A concept of sustainable development for regional land use planning: Lithuanian experience, Technological and Economic Development of Economy 14(1), pp. 51-63.

[31] Kovacic, M., and Dundovic, C. (2009). Criteria for selecting a location for a port of nautical tourism. Pomorstvo. 23(1), pp. 41-65.

[32] Lee, D.-H., Jin, J., and Chen, J.. (2012). Schedule Template Design and Storage Allocation for Cyclically Visiting Feeders in Container Transshipment Hubs. Transportation Research Record: Journal of the Transportation Research Board 2273, pp. 87-95.

[33] Lin, D.-Y., and Huang, K.-L. (2017). An Equilibrium-Based Network Model for International Container Flows. Maritime Policy \& Management 44 (8), pp. 1034-1055.

[34] Lirn, T. C., Thanopoulou, H. A., and Beresford, A. K. (2003). Transhipment Port Selection and Decision-Making Behaviour: Analysing the Taiwanese Case. International Journal of Logistics: Research and Applications 6 (4), pp. 229-244. 
[35] Lirn, T. C., Thanopoulou, H. A., Beynon, M. J., and Beresford, A. K. C. (2004). An Application of AHP on Transshipment Port Selection: A Global Perspective. Maritime Economics \& Logistics 6 (1), pp. 70-91.

[36] Mardani, A., Zavadskas, E. K., Khalifah, Z., Jusoh, A., and Nor, K. MD. (2016). Multiple criteria decision-making techniques in transportation systems: a systematic review of the state of the art literature. Transport 31 (3), pp. 359-385.

[37] Mrvica, A., Jugovic, A., and Kovacic, M. (2015). The role and applicability of multi-criteria procedures in the function of defining the model for connecting the mainland and islands and islands in between. Scientific Journal of Maritime Research 29, pp. 156-164.

[38] Ng, K. Y. (2006). Assessing the Attractiveness of Ports in the North European Container Transshipment Market: An Agenda for Future Research in Port Competition. Maritime Economics \& Logistics 8, pp. 234-250.

[39] Notteboom, T., Parola F., and Satta, G. (2013). Deliverable 1.1: State of the European Port System-Market Trends and Structure Update: Partim Transshipment Volumes. PORTOPIA|D|1.1|DT|2013.05.11. The PORTOPIA Consortium.

[40] Olson, D. (2004). Comparison of weights in TOPSIS models. Mathematical and Computer Modelling. 40, pp. 721-7.

[41] Opricovic, S., and Tzeng, G-H. (2004). Compromise solution by MCDM methods: a comparative analysis of VIKOR and TOPSIS. European Journal of Operational Research. 156, pp. 445-55.

[42] Parsopoulos, K.E., and Vrahatis, M.N. (2005). A Unified Particle Swarm Optimization for solving constrained engineering optimization problems, advances in Natural Computation, Pt. 3, pp. 582-591. Lecture Notes in Computer Science Vol. 3612.

[43] Perez, J. C., Carrillo, M. H., and Montoya-Torres, J. R. (2015). Multi-criteria approaches for urban passenger transport systems: a literature review, Annals of Operations Research 226(1), pp. 69-87.

[44] Rezaei, J. (2015). Best-worst multi-criteria decision-making method. Omega 53, pp. 49-57.

[45] Rezaei, J., Nispeling, T., Sarkis, J., and Tavasszy, L. (2016). A supplier selection life cycle approach integrating traditional and environmental criteria using the best worst method. Journal of Cleaner Production 135, pp. 577-588.

[46] Roy, B. (1968). Classement et choix en présence de points de vue multiples (la méthode ELECTRE). Riro. 2, pp. 5775.
[47] Roy, B. (1978). ELECTRE III: Un algorithme de classement fondé sur une représentation floue des préférences en présence de critères multiples. Cahiers du CERO. 20, pp. 3-24.

[48] Roy, B. (1991). The outranking approach and the foundations of ELECTRE methods. Theory and Decision. 31, pp. 49-73.

[49] Rozic, T., Ogrizovic, D., and Galic, M. (2016). Decision making background for the location of inland terminals. Scientific Journal of Maritime Research 30, pp. 141-150.

[50] Saaty TL. (1977). A scaling method for priorities in hierarchical structures. Journal of Mathematical Psychology. 15, pp. 234-81.

[51] Saaty TL. (1986). Axiomatic foundation of the analytic hierarchy process. Management Science. 32, pp. 841-55.

[52] Saaty TL. (1990). How to make a decision: the analytic hierarchy process. European Journal of Operational Research. 48, pp. 9-26.

[53] Thurstone LL. (1927). A law of comparative judgment. Psychological Review 34, pp. 273.

[54] Tsamboulas, D., Yiotis, G., and Panou, K. (1999). Use of multicriteria methods for assessment of transport projects, Journal of Transportation Engineering 125(5), pp. 407-414.

[55] Ugboma, C., Ugboma,, O. and Ogwude, I. (2006). An Analytic Hierarchy Process (AHP) Approach to Port Choice Decisions-Empirical Evidences from Nigerian Ports. Maritime Economics and Logistics 8 (2), pp. 251-266.

[56] UNCTAD. (2017). Review of Maritime Transport 2017. United Nations Publication.

[57] Wong, L.P., Low, M.Y.H. and Chong, C.S. (2009). An efficient bee colony optimization algorithm for traveling salesman problem using frequency-based pruning. In Industrial Informatics, 2009. INDIN 2009. 7th IEEE International Conference on (pp. 775-782). IEEE.

[58] Yetkili, E., Doğan, E., Baltaoğlu, S., and Salihoglu, I. (2016). Economic Analysis of Container Transhipment in the Eastern Mediterranean Region. International Journal of Environment and Geoinformatics 3 (1), pp. 12-21.

[59] Yeo, G. T., and Song, D. W. (2006). An Application of the Hierarchical Fuzzy Process to Container Port Competition: Policy and Strategic Implications. Transportation 33 (4), pp. 409-422.

[60] Yeo, G.-T., Ng, A. K. Y., Lee, P. T.-W., and Yang, Z. (2014). Modelling Port Choice in an Uncertain Environment. Maritime Policy \& Management 41 (3), pp. 251-267. 